tables, with reference to the value of policies, but has, in my opinion, freed them to the same extent from a slight existing inaccuracy-a consideration which perhaps should tend to make Mr. Todd's tables the more valuable. I am, Sir,

Your very obedient Servant, North British Insurance Office,
Edinburgh, 27th May, 1853. DAVID CHISHOLM.

\title{
ON THE SAME SUBJECT.
}

\section{To the Editor of the Assurance Magazine.}

Sir,-Having recently perused the introduction to the most valuable work of W. T. Thomson, Esq., I met, in page 25, with a foot note referring to a certain paper by Mr. Farren, as inserted in the last number of your Magazine, and was accordingly induced to read that paper itself.

To speak candidly, I read the paper alluded to over and over again, but to my mortification could not discover the results which $\mathrm{Mr}$. Farren is anxious to deduce. This circumstance causes me to apply humbly to you for an explanation on the subject, either by Mr. Farren himself or any of your mathematical readers.

First Mr. Farren says, that Simpson and Dodson imagined that De Moivre assigned $1-i \mathrm{~A}$ as the present value of $\mathfrak{f l}$ payable at the end of the year of death, while he (Mr. Farren) has reason to assert that no such error (?) conld emanate from so celebrated an analyst as De Moivresatisfying himself, that by $1-i \mathrm{~A}$ is meant the present value of $£ 1$ due at the beginning of the year of death. In support of his argument, Mr. Farren quotes part of a paragraph from De Moivre's work, saying, "This conclusion may be deduced from the method he (De Moivre) has adopted in solving the following problem (xVI.), as it occurs in his Treatise on Annuities." Now, unfortunately, the works of Simpson and Dodson are not in my possession; but on perusing De Moivre's work itself, I mnst confess my inability to trace Mr. Farren's conclusions. The paragraph in question of De Moivre's, in extenso, runs thas :--

"Problem xvI.-A borrows a certain sum of money, and gives security that it shall be repaid at his decease, with the interests. To fix the sum which is then to be paid, let the sum borrowed be $s$; the life of the borrower, $M$ years' purchase; $d$ the interest of $f 1$ : then the sum to be paid at A's decease will be $\frac{s}{1-d \mathrm{M}}$; thas, supposing $s=800, \mathrm{M}=11 \cdot 83$,

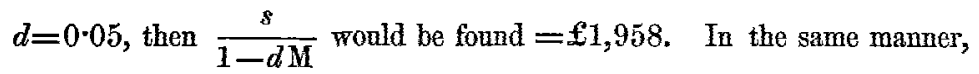
if the sum to be paid at $A$ 's decease was to be an equivalent for his life,

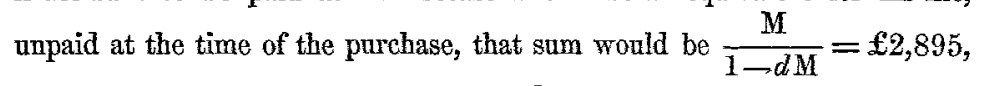
supposing the anmuity received to be $\mathfrak{f 1 0 0}$, as also the life of $\mathbf{A} 11.83$ years' purchase."

You will perceive that the two examples just named-rather essential in the present case-are omitted in the extract made by Mr. Farren, who, 
notwithstanding, proceeds :- "From this it is obvious that $1-d \mathrm{M}$, or in modern notation $1-i \mathrm{~A}$, was considered the present value of $\boldsymbol{E} 1$ at last of the 'interests,' or the beginning of the year of death, or of $£ 1$ at actual death of $A$, with such interest as might have already accrued for the current months and days." Here I stumble: how from this short extract it is obvious that De Moivre meant by $1-d \mathbf{M}$ the beginning of the year of death, I cannot conceive, unless we obtain this obviousness from the fact that its value in numbers agrees with the present value of $£ 1$ reversion payable at the beginning of the year of death, since there is no statement made by De Moivre to this effect. Indeed, I would rather venture to say that De Moivre gives an approximate value for the instant of death, as expressed in his own words, "to be repaid at his decease"; not-to be repaid at the beginning of the year of his decease. Consequently, I cannot reconcile the three terms specified by Mr. Farren to be of equal value : namely, $1-i \mathrm{~A}=$ present value of $£ 1$ at last of the 'interests' = at the beginning of the year of death=at actual death of $A$, with such interest as might have already accrued for the current months and days. From what part of the extract are such inferences to be made? Mr. Farren further proceeds: "Now as half a year's interest is the most probable increment from such a source

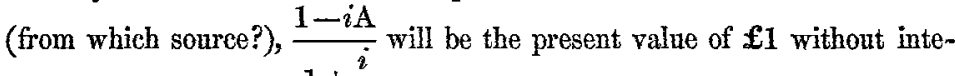
$1+\frac{i}{2}$

rest (why without interest? or does it mean anything else?) at the instant of death, and $\frac{1-i \mathrm{~A}}{1+i}$ that of $\mathfrak{E 1}$ without interest (the same query as the last) at the end of the year of death; consequently the ratio of the latter to the former is as $1: \frac{1+i}{1+\frac{i}{2}}$,"

Mr. Farren thas continued explaining the valne of a portion of a year, saying that for half a year prior to the end of the year of death the formula becomes $\frac{1+i \mathrm{~A}}{1+\frac{i}{2}}$, which subject, as regards the tables of Sang, has already

been handled by Mr. Thomson; but it may be added, that Mr. Farren could have easily discovered in the very De Moivre (3rd edition, London, 1756) that this very question was settled by the latter in his Appendix, page 340 , where he virtually says-

"In the meantime it will be proper to know what part of the yearly rent shonld be paid to the heirs of the late possessor of an annuity, as may be exactly proportioned to the time elapsed between that of the last payment and the very moment of the life's expiring. To determine this, put A for the yearly rent (meaning annuity); $\frac{1}{m}$ for the part of the year intercepted between the time of the last payment and the instant of the life's failing; $r$ the amonnt of $£ 1$ at the year's end : then will $\frac{\frac{1}{r^{n}}-1}{r-1} \mathrm{~A}$ be the sum to be paid." This of course applies to annities, but may be also applied in reversions. 
The tables of Sang have been calculated on the same principle; and, indeed, there is no other method practicable. How would Mr. Farren, according to his own plan, solve the following problem:-

$$
\begin{aligned}
& s=\text { snm, } \\
& d=\text { rate of interest, } \\
& a=\text { amount, } \\
& x=\text { period or duration. }
\end{aligned}
$$

In what time will the sum $s$ amount to $a$, at $d$ compound interest? HERSCHELL FILIPOWSKI.

Standard Life Assurance Office, 3, George Street, Edinburgh. 